\title{
Third cranial nerve palsy and posterior communicating artery aneurysm
}

\author{
Joon-young Kim, Sang-Cheon Choi \\ Department of Emergency Medicine, Ajou University School of Medicine, Suwon, Korea
}

\begin{abstract}
A 64-year-old woman with a history of diabetes mellitus and smoking was admitted to the emergency department because of headache, vomiting, binocular diplopia and right-sided ptosis. Five days earlier, she had a sudden headache of a stabbing nature in the right frontal area, which recurred every 5 hours. The visual analogue scale (VAS) score for pain was 8. Three days later, she noticed binocular diplopia and right-sided ptosis (Fig. 1A, B). Neurologic examination revealed right-sided third cranial nerve palsy with ipsilateral pupil dilation and no other definite focal neurologic deficits. Computed tomography (CT) scan and CT 3-D angiography revealed a 1-cm saccular aneurysm with lobulated contour in the right posterior communicating artery (Fig. 2A, B). On neurosurgical consultation, coil embolization of the aneurysm was performed successfully. The initial symptoms improved after 2 weeks and completely resolved after a 3-month follow-up in the outpatient department.

Unless proven otherwise, acute third cranial nerve palsy with ipsilateral pupillary dilatation is caused by a posterior communicating artery aneurysm. ${ }^{1}$ Concomitant headache is a frequent symptom. ${ }^{1,2}$ Expansion of such aneurysm may cause compression of the outer fibers of third cranial nerve. ${ }^{1,2}$ The pupillomotor fibers are located in the outer portion of this nerve; therefore, the pupil becomes dilated on the affected side. The posterior communicating artery can rupture spontaneously.,4 Treatment involves emergent blood pressure reduction if hypertensive, and neuroimaging and neurosurgical intervention. ${ }^{5}$
\end{abstract}

\section{CONFLICT OF INTEREST}

No potential conflict of interest relevant to this article was reported.

\section{REFERENCES}

1. Newman SA. Aneurysms. In: Miller NR, Newman NJ, editors. Walsh and Hoyt's clinical neuroophthalmology. 5th ed. Baltimore, MD: Williams \& Wilkins; 1998. p.3075-83.

2. Soni SR. Aneurysms of the posterior communicating artery and oculomotor paresis. J Neurol Neurosurg Psychiatry 1974;37:475-84.

3. De la Monte SM, Moore GW, Monk MA, Hutchins GM. Risk factors for the development and rupture of intracranial berry aneurysms. Am J Med 1985;78(6 Pt 1):957-64.

4. Okawara SH. Warning signs prior to rupture of an intracranial aneurysm. J Neurosurg 1973; 38:575-80.

5. Nelson PK, Levy D, Masters LT, Bose A. Neuroendovascular management of intracranial aneurysms. Neuroimaging Clin N Am 1997;7:739-62.
Received: 20 June 2014

Revised: 18 July 2014

Accepted: 20 July 2014

Correspondence to: Sang-Cheon Choi Department of Emergency Medicine, Ajou University School of Medicine, 206 World cup-ro, Yeongtong-gu,

Suwon 443-721, Korea

E-mail: avenue59@ajou.ac.kr

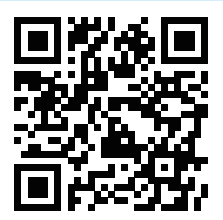

How to cite this article:

Kim JY, Choi SC. Third cranial nerve palsy and posterior communicating artery aneurysm. Clin Exp Emerg Med 2014;1(1): 65-66.

This is an Open Access article distributed under the terms of the Creative Commons Attribution Non-Commercial License (http:// creativecommons.org/licenses/by-nc/3.0/). 

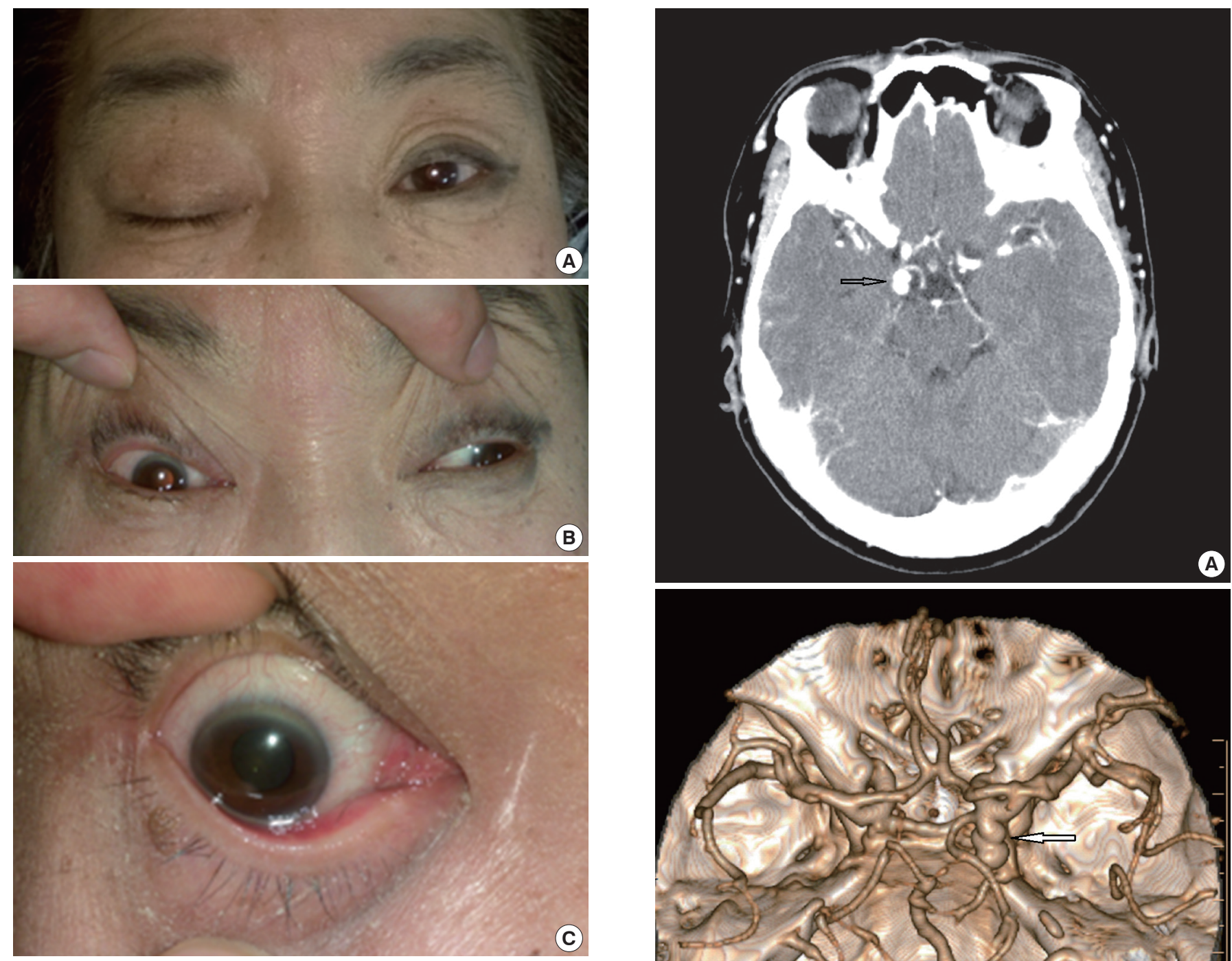

Fig. 1. Right-sided third cranial nerve palsy with ipsilateral pupil dilation was shown in images.

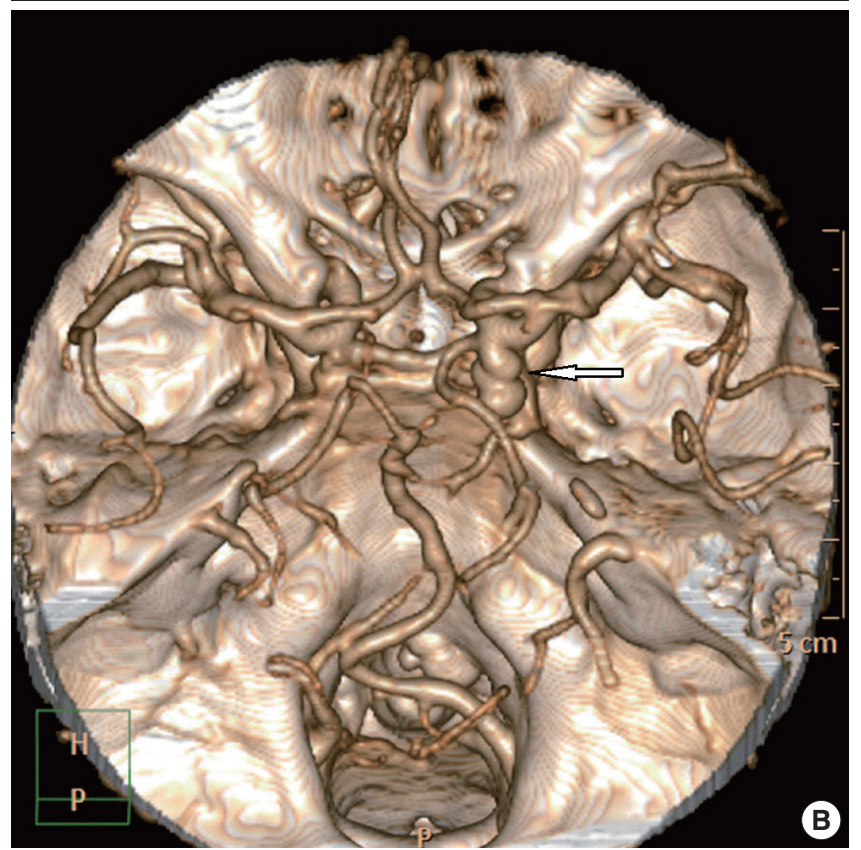

Fig. 2. A 1-cm saccular aneurysm with lobulated contour in the right posterior communicating artery was shown in computed tomography (CT) scan and three-dimensional CT angiography. 